\title{
Teachers Are Key Factors of Universities: Peking Female Higher Normal College 1917-1922
}

\author{
JIANG Lijing \\ Qufu Normal University, Qufu, China; Columbia University, New York, U.S.
}

\begin{abstract}
The successful experiences that cause Peking Female Higher Normal College (PKFHNC) to complete a relatively large scale of talents training task and become the birthplace of modern female intellectuals in early 20th century China in spite of disorder of social circumstance outside and regular educational system inside are as follows. First, with the endeavor of Chen Zhongfan, Dean of Chinese Department, PKFHNC gathered lots of leading scholars both from old school and new school during May Fourth Movement; second, these leading scholars' diversified academic thoughts, political ideas, and educational experiences encouraged students to think freely and critically; finally, their deep concerns about the future of China society, academic disciplines, and women's liberation and education caused all superficial changes and differences of PKFHNC to form an united spiritual power, which promoted this group of female students' development deeply.
\end{abstract}

Keywords: university, faculty, Peking Female Higher Normal College, female college students

\section{Introduction}

Among those famous universities in the Republic of China, Peking Female Higher Normal College (PKFHNC), like Southwest United University (SUU) that is attracting more concerns, is another higher educational institution, which produced a lot of outstanding female elites in spite of a changing and disorder circumstance (Jiang, 2009a). However, contrasted with SUU, which had a series of complete and orderly operating management system, steady and high-qualified faculty members (Ye \& Zhou, 2008), PKFHNC provides a totally different version. Although with all of its regular educational conditions, such as management system, curriculum, faculty member, teaching and learning system, etc., were volatile and chaotic, PKFHNC still completed a relatively large scale of talents training task smoothly and became an important center for Chinese women's higher education and a birthplace of female intellectuals who were playing a positive role in women's liberation and social development in early 20th century China (Jiang, 2009b; Jiang, 2012, pp. 37-66). So, exploring the successful experiences of this unconventional case will undoubtedly help us find the deeper factors affecting the quality of higher education, putting aside regular elements, and then, make contributions to the development of higher education in contemporary China.

Peking Female Higher Normal College (PKFHNC) was the first national higher educational institution for women and also the first one that was established by Chinese in modern China. Its history could be traced back

Project funded by China Postdoctoral Science Foundation (2016M590648).

JIANG Lijing, associate professor of History of Education in China, Ph.D., School of Education Science (SES), Qufu Normal University, China; visiting scholar, Teachers College, Columbia University, New York, U.S. 
to "Imperial Female Normal School" (IFNS), which was built in 1908 during late Qing dynasty, then it was renamed in 1912 to "Peking Female Normal School" (PKFNS). In 1917, it established a Chinese department to prepare for its transformation to a higher normal college (Peking Female Normal School, 1918, pp. 1-7). As long as the transformation was finished in April 1919, its name was officially changed to "Peking Female Higher Normal College" (PKFHNC) (Literature and Art Research Association of Peking Female Higher Normal College, 1919, pp. 4-6), with its first graduates left campus in July 1922. Almost two years later, in May 1924, PKFHNC was upgraded to "National Peking Female Normal University" (NPKFNU) (Sun, 1931). When National Beiping University (NBPU) was built with the combination of nine national higher institutions in 1928, NPKFNU was reorganized into one school of NBPU as "The Second Normal College of National Beiping University" (SNC, NBPU), specially for girls. In 1929, it was renamed as "Female Normal College of National Beiping University" (FNC, NBPU). Then, in July 1931, it was merged into Beiping Normal University (BPNU) (Wu \& Li, 1992, pp. 398, 400, 410-411, 416, 421) and became one of the origins of Peking Normal University (PKNU) (Peking Normal University, 1982), a well known one-hundred-years university in China today.

In this article, "Peking Female Higher Normal College" (PKFHNC) involves 7-year periods of time, which started from 1917, when Chinese department firstly was founded for its transition to a higher normal college, and ended in 1924, at the time that it was upgraded to "Peking Female Normal University". However, this paper will primarily focus on the 5-year periods - 1917-1922, during which the first graduates of Chinese department was on campus.

\section{Engaging Leading Scholars From Different Schools, Including Masters}

"Imperial University in late Qing dynasty was the predecessor of Peking University. Though its name was changed to Peking University thereafter Xinhai Revolution ${ }^{1}$, the university did not change a lot, but with all customs of late Qing passing down before the arrival of President Cai Yuanpei” GU Jiegang ${ }^{2}$ said (Zhong \& Zhu, 1982, pp. 10-17). In fact, GU's comments also illustrated the primary situation of Peking Female Normal School (PKFNS). In 1917, when PKFNS established Chinese Department for its transition to Peking Female Higher Normal College (PKFHNC), the development of the school was still constrained by two rules. First, due to moral code's emphasis on gender discrimination in ancient China and late Qing, PKFNS went on taking "good wives and loving mothers", who always obeyed their parents and husbands without question, as basic educational purposes, which led to its professional education lagging far behind the same degree of male universities. Second, owing to stress on the difference and separation of "academic disciplines" and "technical skills" during the early Republic of China, Chinese Department of PKFNS was defined as a "normal" and "technical" school, which limited its curriculum to several general courses like "Shuowen", "Chinese Origins", as well as skills training courses like Chinese speaking, reading, writing, reviewing, handwriting, etc. (Jiang, 2009; Jiang, 2012, pp. 37-66).

This kind of situation was not changed until the fall of 1918, when Chen Zhongfan became the dean of the

\footnotetext{
1 The Xinhai Revolution (Chinese: 辛亥革命; pinyin: Xīnhài gémìng), also known as the Revolution of 1911 or the Chinese Revolution (though this term may also refer to a number of other events), was a revolution that overthrew China's last imperial dynasty (the Qing dynasty), and established the Republic of China (ROC). The revolution was named Xinhai (Hsin-hai) because it occurred in 1911, the year of the Xinhai (辛亥, metal pig) stem-branch in the sexagenary cycle of the Chinese calendar.

${ }^{2}$ Gu Jiegang, a renowned historian as well as a student at Perking University, who undergone this shift in early modern China.
} 
department. Chen, who styled himself as "Jueyuan", "Jiaoxuan", was admitted to Peking University in 1914 as one of the first batch of students of Philosophy Department. In 1917, Cai Yuanpei, President of Peking University, launched an educational reform, encouraging academic research, highlighting freedom of thought, which resulted in a total improvement of the university. In this context, Chen Zhongfan, who preferred to be a scholar rather than an official, became a loyal follower of President Cai since 1917, and served, with Cai's recommendation, as a faculty member of preparatory Chinese classes and an editor of National History Compiling Office of Peking University after graduation (Chen \& Ke, 1987, pp. 316-317).

In April 1918, Chen accepted an invitation from Fang Huan, President of Peking Female Normal School, to teach classics (Jingxue) and minor learning (Xiaoxue) for students at Chinese Department, PKFNS. Then, In January 1918, he took office of the dean of the department (Literature and Art Research Association of Peking Female Higher Normal College, 1919, p. 4).

From CAI Yuanpei's point of view, the university is a place for "the study of profound knowledge", targeted to produce "great thinkers and big masters" fundamentally. In order to achieve this goal, in addition to asking students to "come for study and hold this purpose in mind", as far as the inner regulation of the university, the key factor is "collecting great works and including masters". Cai pointed out, "hiring pure scholars, asking them to teach students and conduct research with students" was the most important thing that decided whether one university could be transformed into "a place for profound knowledge study" or not. (Gao, 1984, p. 10). Of course, the university that could be "transformed" as CAI mentioned here didn't include all higher educational institutions, but particularly focused on comprehensive universities like PU, such normal schools and colleges as Peking Female Higher Normal School were most likely to be classified as "technical", "professional college" (Gao, 1984, p. 150; Tu, 1997, pp. 300-301).

As a loyal practitioner of Cai, Chen Zhongfan, right after his promotion as the Dean of Chinese Department, started a similar educational reform in PKFNS based on Tsai's ideas on higher education, despite the difference between Peking University and Peking Female Higher Normal School and also that of "academic disciplines" and "technical skills". In an article named "Ways Approaching Academic Progress", he illustrated his ideas clearly on higher educational reform, tracing the same way of thinking as Cai Yuanpei.

Chen argued, though higher education played a significant role in academic progress, the development of academics did "not depend on 'the school", but relied on "several maters' teaching students and searching for the truth". In a word, masters were key factors affecting the quality of universities (Chen, 1919, pp. 11-13). Holding this in mind, Chen made full use of his particular status as the first graduate of Philosophy Department and the editor of National History Compiling Office of Peking University, which provided him a close contact with lots of leading scholars, to build an outstanding faculty team for PKFNS, gathering a large number of masters both in the old school and in the new school during the period of New Culture Movement. Among these leading scholars, there were Liu Shipei, who was named as "Two Shu" (Er Shu) with Chinese Master Zhang Taiyan and even Zhang sang high praise for his academic achievements on classics (Jingxue) and looked at him as a scholar of genius that couldn't meet without one thousand years; Huang Kan, who formed his own style of research and became as popular as his teacher Zhang Taiyan, with their study named by other scholars in the era as "Zhanghuang Study" due to his high academic attainments in Historical Chinese phonology, Chinese exegetics, etc.; Hu Xiaoshi, a famous scholar on classics who was the disciple of several old masters during late Qing dynasty such as Li Meian, Shen Zengzhi, and Wang Guowei and also had a close tie to Huang Kan; Hu Shih, leader of the New Culture Movement, whose representative publication Guidelines on History of 
Chinese Philosophy was regarded as a ground breaking work, which firstly applied western modern research methods to Chinese Philosophy studies systematically; Chen Duxiu (giving lectures), founder of popular journal New Youth ${ }^{3}$ as well as the leader of New Culture Movement; Li Dazhao, one of the founders of Communist Party and also an early important preacher for Marxist thoughts in modern China; Cai Yuanpei (giving lectures), President of Peking University, leading a new fashion of higher education and academia in modern China through his educational reform at Peking University; Zhou Zuoren, leader of modern prose in modern China who preferred New Literature rather than Old Literature though as a disciple of master Zhang Taiyan, who was very good at Old literature; Chen Hengzhe, the first female professor, who was good at western history study, at Peking University, as well as the first supporter to Hu Shih's Literaturary Reform; Fu Tong, a disciple of Bertrand Russell and a professor at Philosophy Department, Peking University; Zhang Yaoxiang, one of the key founders of psychology in modern China; Wu Yifang, future president of Jinling Female University; Deng Cuiying, president of Peking Higher Normal College, Lin Liru, future president of Peking Normal University, and other famous scholars on education who were teaching in Peking Higher Normal College, such as Han Dingsheng, Liu Yizhong, et al.

These leading scholars' arrival made Chinese Department of PKFHC form a similar academic climate as liberal departments of Peking University, including a study-based educational purpose, outstanding faculty members with lots of masters, curriculum with both defined Chinese knowledge and western disciplines, and a positive academic climate encouraging thinking and researching freely and critically as well.

Table 1

Teacher List and Curriculum Schedule of Chinese Department of Peking Female Normal School (1917.8-1918.7)

\begin{tabular}{|l|l|l|l|}
\hline Name & Gender & SuPKect, Duty & Native place \\
\hline Dai Li & Female & Chinese, Class Teacher & Yuhuan, Zhejiang \\
\hline Pan Shusheng & Male & Chinese, Selected Works & Rugao, Jiangsu \\
\hline Deng Cuiying & Male & Education, Logics & Minhou, Fujian \\
\hline Wang Jiaji & Male & Geography, History & Dantu, Jiangsu \\
\hline
\end{tabular}

Source: Sorted out from: Peking Female Normal School (1918), A Guide to Peking Female Normal College. Peking: Peking Female Normal College, pp. 91-94. Cheng Junying (2004), The Autobiography of Cheng Junying. Zhu Jieren and Dai Congxi. Selected Papers in Memory of Cheng Junying. Shanghai: East China Normal University, pp. 281-289. Literature and Art Research Association of Peking Female Higher Normal College. (1921), A Guide to Curriculum and Professors of Chinese Department. Journal of Literature and Art Research Association of Peking Female Normal College, Vol. 3, Appendix 5-9.

Table 2

Teacher List and Curriculum Schedule of Chinese Department of Peking Female Higher Normal College (1917.8-1922.7)

\begin{tabular}{|l|l|l|l|}
\hline & Term & Teacher & Courses \\
\hline \multirow{4}{*}{$\begin{array}{l}\text { Department of } \\
\text { Chinese, PKFNS }\end{array}$} & $\begin{array}{l}\text { The First Year } \\
(1917.8-1918.7)\end{array}$ & Dai Li & Chinese, Class Teacher \\
\cline { 2 - 3 } & Pan Shusheng & Chinese, Selected Works \\
\cline { 3 - 4 } & Deng Cuiying & Education, Logics \\
\cline { 2 - 4 } & Wang Jiaji & Geography \\
\cline { 3 - 4 } & & History \\
\hline
\end{tabular}

\footnotetext{
${ }^{3}$ New Youth (Chinese: 新青年; pinyin: Xīn Qīngnián) was an influential Chinese magazine in the 1910s and 1920s that played an important role in initiating the New Culture Movement and spreading the influence of the May Fourth Movement.
} 
(table 2 continued)

\begin{tabular}{|c|c|c|c|}
\hline & Term & Teacher & Courses \\
\hline & \multirow{13}{*}{$\begin{array}{l}\text { The Second Year } \\
(1918.8-1919.7)\end{array}$} & \multirow{3}{*}{ Huang Kan } & History of Literature \\
\hline & & & Ancient Selected Works \\
\hline & & & Selected Poem and Origins \\
\hline & & Liu Shipei & General Literature \\
\hline & & Qian Zhenchun & Pedagogy \\
\hline & & \multirow{3}{*}{ Chen Zhongfan } & Psychology \\
\hline & & & Academic Origins $1 \cdot$ Classics \\
\hline & & & Academic Origins $2 \cdot$ Independent Thinkers' Works \\
\hline & & \multirow{2}{*}{ Gu Zhenfu } & Chinese Philology \\
\hline & & & Selected Modern Literature \\
\hline & & \multirow{2}{*}{ Wang Jiaji } & History $\cdot$ Chinese History \\
\hline & & & Chinese Geography \\
\hline & & Pan Zhenbao & Music \\
\hline \multirow{26}{*}{$\begin{array}{l}\text { Department of } \\
\text { Chinese, PKFNC }\end{array}$} & \multirow{26}{*}{$\begin{array}{l}\text { The Third Year to the Fifth Year } \\
(1919.8-1922.7)\end{array}$} & Hu Shih & General Western Philosophy \\
\hline & & Zhou Zuoren & History $\cdot$ History of Western Literature \\
\hline & & Fu Tong & Ethics $\cdot$ History of Western Ethics \\
\hline & & Li Taifen & History $\cdot$ Western History \\
\hline & & Qian Zhenchun & Geography \\
\hline & & Li Dazhao & Philosophy $\cdot$ Sociology \\
\hline & & Deng Cuiying & Education $\cdot$ Teaching Methods \\
\hline & & Lin Liru & Education $\cdot$ History of Education \\
\hline & & Han Dingsheng & Education $\cdot$ Pedagogy \\
\hline & & Mao Bangwei & Ethics $\cdot$ Practice Ethics \\
\hline & & Liu Yizhong & Ethics $\cdot$ Logics \\
\hline & & Zhang Xuan & Phonology \\
\hline & & Zheng Shenyin & House Keeping \\
\hline & & Pan Zhenbao & Music \\
\hline & & & Selected Works \\
\hline & & Chen Zhongfan & Selected Stylistic Works \\
\hline & & & Chinese Academic Origins \\
\hline & & Hu Xiasshi & Selected Works \\
\hline & & Hu Arausint & Rhetoric \\
\hline & & & Selected Works \\
\hline & & & Chinese Philology \\
\hline & & Gu Zhenfu & Poetry $\cdot$ Selected Poetry and Verse \\
\hline & & & Poetry $\cdot$ Poetics and History of Poetry \\
\hline & & & Selected Poetry \\
\hline & & Wang Jiaii & History of Literature \\
\hline & & ving Jiajt & Chinese History \\
\hline
\end{tabular}

Source: Sorted out from: Peking Female Normal School. (1918), A Guide to Peking Female Normal College. Peking: Peking Female Normal College, pp. 91-94. Literature and Art Research Association of Peking Female Higher Normal College. (1919), Curriculum Schedule and Teacher List in 1919. Journal of Literature and Art Research Association of Peking Female Normal College, Vol. 1, Record 5. Literature and Art Research Association of Peking Female Higher Normal College. (1921), A Guide to Curriculum and Professors of Chinese Department. Journal of Literature and Art Research Association of Peking Female Normal College, Vol. 3, Appendix 5-9. Cheng Junying (2004), The Autobiography of Cheng Junying. Zhu Jieren and Dai Congxi. Selected Papers in Memory of Cheng Junying. Shanghai: East China Normal University, pp. 281-289. Su Xuelin (1996), The Autobiography of Su Xuelin. Nanjing: Jiangsu Literature Publishing House, p. 311. 


\section{Thinking Freely and Tolerance}

In Cai's opinion, coinciding with the above principle- "collecting great works and including masters", another important principle that universities should obey in order to be transformed into "a place for profound knowledge study" was "free thinking and tolerance". Cai said, "Leaders of universities should let different schools of thoughts - whatever it was, if only it was based on some kind of logic, and was not eliminated naturally--go freely and debate with one another", and "that was one university should be" (Gao, 1984, pp. 272-275).

Also influenced by Cai's liberalism ideas, Chen Zhongfan believed that conducting research is the mission of the university. Moreover, from his point of view, research "prefers competition rather than authoritarian since competition encourages difference and diversity, with which the right and the wrong come up consequently. In this case, conducting research means comparison, searching for the right and the wrong, and then, the truth appears in the end." Thus, asking scholars with different research ideas and political opinions to debate with each other freely was what the university should be alike (Chen, 1919, pp. 11-13). Hence, after May-Fourth Movement, with the rapid growth of a batch of new intellectuals such as Hu Shih, Li Dazhao, et al., Chen Zhongfan initiatively gave up sectarian bias (Menhu Zhijian) between the new school and the old school, and started to invite scholars from both sides to PKFHNC. As a result, an academic atmosphere that encouraged the freedom of thought and debate appeared.

Firstly, due to conflicts of academic ideas, the faculty member of PKFHNC experienced a rapid shift from "Tongcheng School" to "Wenxuan School", and then to "New Literature School", along with a hot debate among these three.

For instance, Dai Li and Pan Shusheng, two key Chinese teachers at Chinese department of PKFNS in 1917, emphasized "the three obedience and the four virtues"4 (Zhu \& Dai, 2004, pp. 281-289) as well as focusing on the prose written by Eight Scholars between Tang and Song Dynasty in their classes because both of them believed in the creed of "Tongcheng School"- "following the academic tendency of Chengzhu and the writing style of Hanou", and holding "writing carry doctrine" in mind as well (Guo, 2006, pp. 67-73). However, contrasted with those above "Tongcheng" teachers, Huang Kan and Liu Shipei, two leaders of "Wenxuan School" who were teaching at Chinese department of PKFNS in 1918, advocated writings of Wei-Jin and Six Dynasties, stressed on parallel prose as the authentic style of literature, and directed students to study classics (jingxue) with the method of textual study (Wu, 2003, pp. 51-57). In early 20th century, "Wenxuan School" led by Huang and Liu, launched a criticism movement to "Tongcheng School", which was dominate academia at that period of time, and aroused a hot debate between prose and parallel prose consequently (Jiang \& Fang, 2004). Even though, both sides agreed that "classical Chinese prose" (Wenyanwen) was the unique authentic language of gentleman's literature, while the vernacular (Baihuawen), as the special language of pop literature, was not appeal to refined taste. Thereafter, Hu Shih, Li Dazhao, Zhou Zuoren, et al., who taught at PKFHNC since the fall of 1919, were most leaders and backbones of "New Literature School" and "New Thought School". In order to overturn the orthodox status of classical Chinese prose and expend the use of vernacular, they targeted "Tongcheng School" and "Wenxuan School" as their common enemies, denounced them as

\footnotetext{
${ }^{4}$ The three obediences and the four virtues; three obediences (in ancient China a woman was required to obey her father before marriage, and her husband during married life and her sons in widowhood) and four virtues (fidelity, physical charm, propriety in speech and efficiency in needle work) — wifely submission and virtue.
} 
"Tongcheng Fallacy" and "Xuanxue Uber", and called "classical Chinese prose" as "dead words", named literature written in classical Chinese prose as "dead literature" (Chow Tse-tsung, 1960, pp. 260-279). Holding this in mind, they not only taught students New Literature, western academic disciplines, but also stimulated students to study Chinese ancient academics and culture through western scientific methods (Feng, 1973, pp. 22-25; Su, 1996, p. 311; Peking Normal University, 1984, pp. 124-141).

Secondly, there was a great diversity of political opinions and party affiliations of PKFHNC's faculty.

For example, Huang Kan and Liu Shipei were largely different from each other in their political opinions and party affiliations though both were representatives of "Wenxuan School". Huang Kan used to take part in T'ung-meng $\mathrm{Hui}^{5}$ and devoted himself to anti-Qing revolution in his early years. Then, he fled to Japan due to Qing government's arrest warrant. During his stay in Japan, he became a disciple of classics master Zhang Taiyan and started to conduct research with Zhang and take participate in anti-Qing revolution actively at the same time. In 1911, he wrote an article "Big Turmoil: Wonderful Medicine to Cure China", published in newspaper, which was considered as the first voice for Xinhai Revolution. However, deeply frustrated by Yuan Shikai's stealing nation and Zhang Taiyan's being captured, Huang made his mind to give up politics and dedicate himself to academic studies soon after the foundation of the Republic of China (Chen \& Tang, 2006, pp. 14, 45-82). Contrasted with Huang's positive political attitude, Liu Shipei's political position wasn't clear at all. Though he had also been a member of T'ung-meng Hui and participated in anti-Qing revolution actively in his early years, Liu betrayed the Revolutionary Party by assisting Duanfang to suppress the movement of Protecting Railway before the eve of Xinhai Revolution. Furthermore, as one of the "Six Gentlemen" of "Association for Stability" (Chouan Hui), Liu supported Yuan Shikai to restore the imperial system thereafter the establishment of the Republic of China (Wan, 2003, pp. 269, 139-201, 240-258, 266), which was why Huang Jie, a colleague of Liu at Peking University, criticized Liu as a "changeable snob".

Additionally, shortly after May Fourth movement, there was a great division among new intellectuals. Hu Shi and Li Dazhao, who used to be comrade-in-arms in "New Literature School", went their own separate ways due to different political ideas. These two not only started a long-term debate on "Questions and Systematic Theories" (Wenti and Zhuyi), but also caused new intellectuals to split into two opposing sides, the "right wing" and the "left wing" (Peng, 1984, pp. 470-499; Xiao, 1995, p. 258).

Finally, there was also great difference in their educational experiences. Although most teachers at PKFHNC had overseas backgrounds, as far as the nations they studied, they could be divided into two schools-"Dongyang School", who completed their overseas learning in Japan, and "Werstern (Xiyang) School", who studied in Europe and U.S.

For instance, teachers such as Huang Kan, Liu Shipei, Chen Duxiu, Li Dazhao, Zhou Zuoren, Lin Liru, and Liu Yizhong, et al. belonged to "Dongyang School", who finished their overseas study in Japan, while teachers like Hu Shih, Chen Hengzhe, Fu Tong, Zhang Yaoxiang, Wu Yifang, et al. were all major intellectuals of "Western (Xiyang) School", who studied in Europe or U.S. and received a relatively direct training of modern western academics. As far as other teachers like Deng Cuiying, Han Dingsheng, et al., they got their overseas training first in Japan, and then transferred to U.S. later on.

\footnotetext{
${ }^{5}$ The T'ung-meng Hui, also known as the Chinese United League, United League, Chinese Revolutionary Alliance, Chinese Alliance and United Allegiance Society, was a secret society and underground resistance movement founded by Sun Yat-sen, Song Jiaoren, and others in Tokyo, Japan, on 20 August 1905. It was formed from the merger of many Chinese revolutionary groups in the late Qing Dynasty.
} 
Moreover, given the particular state, university they entered, there were still a lot of differences in the same school. For example, among "Western School" teachers, Cai Yuanpei went to Germany, Fu Tong visited England, while most others such as Hu Shih, Chen Hengzhe, Zhang Yaoxiang, et al. started their overseas study in U.S.

Additionally, there was even a great diversity in their discipleship. Both Huang Kan and Zhou Zuoren were students of the classics master Zhang Taiyan, Liu Shipei received a serious family education from an early age, and $\mathrm{Hu}$ Xiaoshi was taught by several old masters during late Qing dynasty such as Li Meian, Shen Zengzhi, and Wang Guowei, while Hu Shih was the student of John Dewey, a world-famous educational thinker in U.S., and Fu Tong got his Ph.D. degree on western philosophy with the guidance of Bertrand Russell, a world-known philosopher in England.

\section{Preparing My Buffcoat and Weapons, and Marching Along With You}

"I will prepare my buffcoat and sharp weapons, and will march along with you." This was what Lu Xun wrote for the 24 female college students during "Peking Female Normal University Tempest" in 1925. By citing this sentence of No Clothing, Book of Songs, Lu Xun showed his strong decision to fight against the authoritarian of Beiyang government side by side with this group of female students. However, in fact, these words not only expressed Lu Xun's personal position, but also represented the common attitude of both late Qing intellectuals and May Fourth intellectuals to successors and women. Actually, despite the difference of academic ideas, political opinions, educational experience among these scholars, their endeavors to open a road for the development of China society and academia were the same (Chen, 1998, Introduction, p. 5).

No matter late Qing intellectuals as Huang Kan and Liu Shipei, who aimed to restore the lost teachings of the past sages and support the declining academics, or May Fourth intellectuals like Hu Shih, who devoted himself to "enlightening the nation, and creating a new culture", they usually hold their believes of enlightening masses and changing society into their studies after they left far away from the social power center and retreated to the academia. Driven by such a state of mind, they not only maintained lifelong academic interests, but also paid close attention to discovering talents anytime and anywhere. Once they found the talent, they'd like to encourage them constantly and support them by any means. (Yu, 2001, pp. 1-13; Chen, 1998, Introduction; Xu, 2004, pp. 79-88)

It should be added that, the identification of women with backwardness and dependency acquired a new urgency in the May Fourth period (1915-1927). As imperialist aggressions intensified, the victimized woman became the symbol of the Chinese nation itself, "raped" and dominated by virile foreign powers. In a word, women's subjugation to the patriarch epitomized the savageries of ancient China, the roots of its present-day humiliation. The image of the victimized feudal woman was vested with such powerful nationalist sentiments. Women's enlightenment, from the point of view of many leading intellectuals, thus became a prerequisite for the political liberation of the whole nation as well as for China's entrance into the modern world (Ko, 1994, Introduction, pp. 1-2).

In such context, though different intellectuals have different opinions on the way to social change and women's liberation, they deeply agreed with each other on the significant role that women's liberation and education played to the construction of a modern China. As a result, they showed great concerns about this group of female students, who were the first female college students produced by the first national higher educational institution for women in modern China. 
For instance, when Liu Shipei held a position at Chinese department, PKFNS during August 1918 to July 1919, the course he taught was Literature General, two hours a week (Literature and Art Research Association of Peking Female Higher Normal College, 1919, p. 5). However, there was a special meaning for the ordinary 2-hours class especially at a time when he already had a very tough schedule both in teaching and research at Peking University, as well as his lung disease, which had extended in a late period and "prevented him from speak loudly", caused his death on November 20,1919, only several months after he resigned his teaching at PKFNS (Wan, 2003, p. 266).

What made Liu insist to arrive at PKFNS, regardless of his bad disease and heavy schedule, was his strong desire to "transmit knowledge" with "the declination of classics". Moreover, he made a very careful preparation before teaching at PKFNS (Wu, Yao, \& Liang, 2001, pp. 191-192), even if he, as a classics master, usually gave lectures smoothly without a piece of papers in hands at PU (Yang, 1988, p. 661), which definitely proved how attentive and careful he was when taught at PKFNS.

Besides, what made Huang Kan, another representative of "Wenxuan School", give up politics and dedicate his life into study was not "just study simply for study", but consider study as a crucial way to "save race and defend country". He insisted, all studies should take "morality", "health", and "welfare" as purposes, conducting research was to "Make a mind for Heaven and Earth, set up the Tao for human beings, restore the lost teachings of the past sages, and build a peaceful world for all future generations" (Chen \& Tang, 2006, p. 39). Holding this in mind, Huang accepted a Professor offer from Peking University and taught History of Chinese Literature in the autumn of 1914 (Sima, 2005, p. 90). Though one of the preppie at PU, Tao Xisheng, "was afraid to audit Huang's classes" (Chen \& Xia, 1998, p. 190) because of his prestige and strict demands on students, Huang seemed to be kind and warm, and was regarded as a "gifted scholar" who talked about text exegesis and classics now and then, from the perspective of the female student at PKFNS (Wu, 2003, pp. 51-57).

Another example, though both Hu Shih (Hu, 1984, pp. 351-407), who taught at PKFNC from August 1919 to June 1920, and Li Dazhao (Edition Committee of Li Dazhao, 1984, pp. 110-111, 116, 119), who started his teaching at PKFNC since the autumn of 1920 (Literature and Art Research Association of Peking Female Higher Normal College, 1921, pp. 5-9) had tough schedules during this particular period of time shortly after they wining their fames during May Fourth Movement, which caused such as hospitable person as Hu Shih have to remind visitors of 5-minutes stay limit in his study (Hu, 1984, p. 407), they still arrived at PKFNC with invitation from Chen Zhongfan, and paid special attention to these female students' education.

According to Hu Shih's Dairy, besides regular teaching, Hu went to PKFHNC many times to "give lectures", "watch dramas", etc., and also took a long time to write a 6,000-words biography for a common female student named Li Chao (Cao, 2001, pp. 12-24, 30, 43). As long as female students at PKFHNC visited him asking for directions, he would like to break the 5-minutes limit and let them stay longer (Zhu \& Dai, 2004, pp. 281-289). Although it's impossible for this group of female students to give someone, who was so busy as Hu Shih, a deep impression with only short contacts two hours a week, Hu, surprisingly, could call their names properly even after 35 years (Feng, 1973, pp. 22-25). Moreover, Hu's concerns about his students were beyond limits of ideology, time, and space. In 1957, Simple Edition of History of Chinese Literature, the representative book of Feng Yuanjun, an old student of Hu at PKFHNC, was published by Kaiming Bookstore. However, the boss was arrested and the book was banned in Taiwan because of its discussion of "Proletarian literature". On hearing the news, Hu lost his temper, which seldom happened for many years, and tried his best to make the 
book be published in Taiwan eventually (Yan, 2008, pp. 139-140, 365). Meanwhile, his old student Feng Yuanjun had to write papers to criticize Teacher Hu Shih for his "reactionary thought" under particular political circumstance (Feng, 1955).

In September 1920, Li Dazhao and his family moved to No. 35 Backyard, Shi Fuma Street, Xicheng District, Peking (Edition Committee of Li Dazhao, 1984, p. 114), only a few blocks away from PKFHNC campus, which made it possible for Li, besides regular teaching, to take part in student activities during spare time. From October to December 1921, he gave three literatures on the way to improve women's lives. (Research Association of Li Dazhao in China, 2006a, pp. 330-334, 336-344; Research Association of Li Dazhao in China, 2006b, pp. 8-9). And, at the end of his course "Ethics", he also encouraged female students to adapt old poem Peacock Flying Southeast to modern drama and perform in public, during which including the selection, adaptation, practice, and performance of the play were all under Li's dedicated and detailed guidance. Finally, when it was performed on stage in 1921, Li watched the play with his family and sang high praise for their performance (Li, 1981, pp. 73-76; Zhu \& Dai, 2004, pp. 317-320). In September 1921, when Lin Baoquan and Sumei, two female students at PKFHNC, went to France for overseas study while doing part-time job to support their study, Li directly wrote a letter to Zhou Xuan, the founder of Agence Paris Press, asking him to take care of their study and lives (Li, 1999, p. 655), which undoubtedly showed his special concerns about this particular group of students.

\section{Conclusion and Discussion}

In fact, their concerns about female students represented the common attitudes of both late Qing intellectuals and May Fourth intellectuals to women. In October 1919, one common student at PKFHNC named Li Chao died, which shocked the total Peking Academia. In hence, Cai Yuanpei, Hu Shih, Li Dazhao, Chen Duxiu, Jiang Menglin, and Liang Shuming, along with other famous scholars in the era, attended the memorial ceremony of Li Chao, and gave speeches. As Hu Shih said, "The undergoing of Li Chao could be used to portray the actual lives of countless women in China", Li Chao "might be considered as an important victim in the history of Chinese women's rights". (Hu Shih, 1998, p. 503). Through the death of Li Chao, they criticized traditional moral codes and social system persecuting women in China, and provided with different kinds of plans for women's liberation and social transformation in early modern China (Cai, Chen, \& Liang, 1919).

In a word, what made PKFHNC foster a lot of women frontiers successfully, despite the outer rapid shift of China society and the inner basic change of educational conditions from 1917 to 1922, was primarily owing to its outstanding faculty, including a large number of leading scholars from different schools during New Culture Movement. All characteristics of these leading scholars such as their profound achievements, diversified thoughts and research styles, deep concerns about the development of China society and academics, and their special attention to women's liberation and education as well, had made all kinds of variation and differences of the college into a positive spiritual power, which, consequently, not only created a similar academic landscape as Peking University, but also gave a great influence to the girls. In general, the success of PKFHNC reminded us of the famous comments, made by Mei Yiqi, President of Qinghua University, which was another leading university in early modern China, "Faculty is the key factor affecting the educational quality of one university", "the university's success doesn't depend on big mentions, but relies on masters" (Liu \& Huang, 1993, p. 132). 


\section{References}

Cai, J. M, Chen, Zh. F., Liang, Sh. M, et al. (1919). Speeches on Miss Li Chao's Memorial Ceremony. Moring Newspaper, December 13, vol. 7; December 17, vol. 7; December 22, vol. 5.

Cao, B. Y. (2001). Complete Works of Hu Shih's Dairy (The Third Volume). Hefei: Anhui Education Publishing House.

Chen, P. Y. (1998). Creation of modern China's academics: Case studies on Zhang Taiyan and Hu Shih. Beijing: Peiking University Press.

Chen, P. Y., \& Xia, X. H. (1998). The past of Peking University. Beijing: Life, Reading, and New Knowledge Publishing House.

Chen, Q. F., \& Tang, W. (2006). Huang Kai’s Life History and Studies: Learning records in Liangshou House (second edition). Beijing: Life, Reading, New Knowledge Press.

Chen, Zh. F. (1919). Approaching to academic progress. Journal of Literature and Art Research Association of Peking Female Normal College, Vol. 1, Lecture 11-13.

Chen, Zh. F., \& Ke, F. (1987). Qinghui collection. Beijing: Booklist Materials Press.

Chow Tse-tsung. (1960). The May Fourth Movement: Intellectual revolution in modern China. Cambridge, Massachusetts: Harvard University Press.

Edition Committee of Li Dazhao. (1984). Chronicle of Li Dazhao. Shanghai: East China Normal University Press.

Feng, A. Q. (1973).Collection of mementos for Mr. Hu Shih. Taibei: Taiwan Student Press.

Feng, Y. J. (1955). Criticizing Hu Shih's study on journey to the West. Literature, History, and Philosophy, 7, 36-44.

Gao, P. Sh. (1984).Complete Works of Cai Yuanpei (The Third Volume). Beijing: Zhonghua Press.

Guo, Y. L. (2006). Academic background of debate between Wenxuan School and Tongcheng School. Record of Peking University Graduates, 86.

Hu Shih. (1998). Selected works of Hu Shih (The Second Volume). Peking: People's Literature Publishing House.

Hu, S. P. (1984). Chronicle of Mr. Hu Shih (The Second Volume). Taibei: Lianjing Publishing House.

Jiang, L. J. (2009a). From margin to center: Reinterpretation of Peking Female Normal Higher College. Higher Education Studies, $11,80-86$.

Jiang, L. J. (2009b). Peking Female Higher Normal College: An unconventional case. Education Journal, 5, 18-25.

Jiang, L. J. (2012). In the shadow of history: Memories of the May Fourth Generation of Women Intellectuals. Beijing: Educational Science Publishing House.

Jiang, X. J., \& Fang N. Sh. (2004). Review on the One Hundred History of the Tongcheng School Studies. Anhui History, 6, 91-99.

Ko, D. (1994). Teachers of the inner chambers: Women and culture in seventeenth-century China. Stanford, Calif.: Stanford University Press, Introduction.

Li, D. Zh. (1999). Complete works of Li Dazhao. Shijiazhuang: Hebei Education Publishing House.

Li, X. H. (1981). Memory of my father: Li Dazhao. Shanghai: Shanghai Literature and Art Publishing House.

Literature and Art Research Association of Peking Female Higher Normal College. (1919). Record on this school year of Peking Female Higher Normal College. Journal of Literature and Art Research Association of Peking Female Normal College, Vol. 1, Record 4-6.

Literature and Art Research Association of Peking Female Higher Normal College. (1921). Curriculum schedule and teacher list. Journal of Literature and Art Research Association of Peking Female Normal College, Vol. 3, Appendix.

Liu, Sh. L., \& Huang, Y. F. (1993). Selected works on education of Mei Yiqi. Beijing: People's Education Publishing House.

Peking Female Normal School. (1918). A guide to Peking Female Normal College (pp. 91-94). Beijing: Peking Female Normal School Press.

Peking Normal University. (1984). May Fourth Movement and Peking Higher Normal Universities. Beijing: Peking Normal University Press.

Peking Normal University. (1982). The History of Peking Normal University: 1902-1982. Beijing: Peking Normal University Press.

Peng, M. (1984). The history of May Fourth Movement. Beijing: People's Publishing House.

Research Association of Li Dazhao in China. (2006a). Complete works of Li Dazhao (The Third Volume). Beijing: People Publishing House.

Research Association of Li Dazhao in China. (2006b). Complete works of Li Dazhao (The Fourth Volume). Beijing: People Publishing House. 
Sima. Ch. J. (2005). Chronicle of Huang Kan. Wuhan: Hubei People's Publishing House.

Su Xuelin (1996). Autobiography of Su Xuelin. Nanjing: Jiangsu Literature Publishing House.

Sun, S. Q. (1931). History guideline of Peking Female Normal University. 1931 Graduates of the Second Department of National Normal University (Eds.), The Second Department of National Normal University: Graduates List of Peking Female Normal University. Peking: Xiehua Publishing House.

Tu, Y. G. (1997). On the history of higher education in China. Wuhan: Hubei Educational Publishing House.

Wan, S. G. (2003). Chronicle of Liu Shipei. Yangzhou: Guangling Press.

Wu, H. L., \& Li, H. (1992). Historical materials of Peking Higher Educational Institution (The First Collection). Beijing: Peking Normal College Publishing House.

Wu, Q. L. (2003). Chen Zhongfan: A historian of the history of literature. Nanjing: Nanjing University Press.

Wu, X. L., Yao, K. F., \& Liang, Sh. An. (2001). Letter collection of Chen Zhongfan's friends. Nanjing: Jiangsu Guji Publishing House.

Xiao, Ch. R. (1995). Peking University and May Fourth Movement. Beijing: Peiking University Press.

Yan, R. X. (2008). Biography of Feng Yuanjun. Beijing: People's Literature Publishing House.

Yang, L. G. (1988). Works of Mr. Yang Lianggong. Taibei: Commercial Press.

Ye, T. X., \& Zhou, H. (2008). Administration thought of Southwest United University and its inspiration to the reform of universities in modern China. Higher Education Study, 3, 89-93.

Yu, Y. Sh. (2001). Discussing studies and poetry 20 years: Letters between Hu Shih and Yang Liansheng. Hefei: Anhui Educational Publishing House.

Xu, J. L. (2004). Ten papers on intellectuals in China. Shanghai: Fudan University Press.

Zhong, Sh. H., \& Zhu, Ch. (1982). The past universities. Changsha: Hunan Education Publishing House.

Zhu, J. R., \& Dai, C. X. (2004). Selected papers in memory of Cheng Junying. Shanghai: East China Normal University Press.

Zhu, Y. H. (1989). Historical materials of modern China school systems (The Second Volume). Shanghai: East China Normal University Press. 